\title{
Spectroscopic Studies on Charge Transfer Complexes of Chloranil with Novel 6-(Trifluoromethyl)furo[2, 3-b] pyridine-2-carbohydrazide Derivatives
}

\author{
VENKATESHAM DONGALA*, RAMESH MACHA and PARTHASARATHY TIGULLA \\ Department of Chemistry, University College of Science, Saifabad, Osmania University, \\ Hyderabad, India \\ venkychem2@gmail.com
}

Received 16 November 2013 / Accepted 29 December 2013

\begin{abstract}
A sensitive spectrophotometric method was employed to study the charge transfer complex of chloranil with 6-(trifluoromethyl)furo[2, 3-b]pyridine-2-carbohydrazide derivatives (TFC). The method is based on the reaction of these drugs as $n$-electron donors with the pi-acceptor 2,3,5,6-tetrachloro-1,4-benzoquinone. The obtained coloured charge transfer complex was measured at $412 \mathrm{~nm}$ by UV-Vis spectrophotometer. The obtained complexes were confirmed by ${ }^{1} \mathrm{H}$ NMR and IR spectral analysis. The proposed procedure could be applied successfully to the determination of the association constants and standard free energy changes using Benesi-Hildebrand plots.
\end{abstract}

Keywords: Charge transfer complex, Chloranil, Association constant, Gibbs free energy.

\section{Introduction}

Intermolecular charge transfer complexes are formed when electron donor and electron acceptors were interacting. It is a general phenomenon in organic chemistry ${ }^{1-2}$. Chloranil is sensitive to excessive light and heat. It is incompatible with strong oxidizing agents. It is a good electron acceptor. Charge transfer complexes have unique absorption bands in the ultraviolet-visible region. Some of the charge transfer complexes containing chloranil as an acceptor have been reported ${ }^{3-10}$.

The molecular interactions between electron donors and acceptors are generally associated with the formation of intensity colored charge transfer complexes, which absorb radiation in the visible region ${ }^{11}$. 6-(Trifluoromethyl)furo[2,3-b]pyridine-2- carbohydrazide (TFC) derivatives are good $n$-electron donors and form charge transfer complexes with pi-acceptors. These are known to yield charge transfer complexes and radical anions with a variety of electron donors ${ }^{12-13}$. The stable 2,3,5,6-tetrachloro-1,4-benzoquinone (chloranil) was formed charge Transfer complex ${ }^{14}$ with the p-toluidine are shown in Scheme 1. TFC derivatives are chemical agents that exert their principle pharmacological and therapeutic effects by acting at peripheral sites to either enhance or reduce the activity of components of the sympathetic division on autonomic nervous system ${ }^{15}$. 


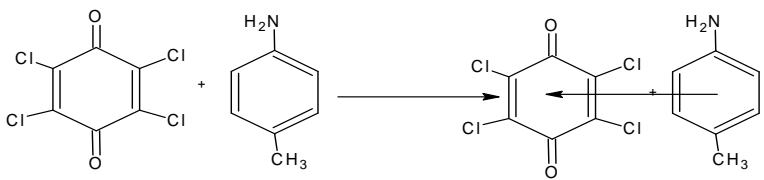

\section{Experimental}

Scheme 1

2,3,5,6-Tetrachloro-1,4-benzoquinone, $L$-ascorbic acid, 1,4-dioxane, acetone, TFC derivatives were of AR grade and Systronics Version 1.1PC based Double Beam Spectrophotometer 2202 with matched, $1 \mathrm{~cm}$ Quartz cuvettes, Digital weighing balance, calibrated flasks, beakers were used. Into a $50 \mathrm{~mL}$ calibrated flask, $250 \mathrm{mg}$ of 2,3,5,6-tetrachloro-1,4-benzoquinone (chloranil) was dissolved in 1,4-dioxane. It was then diluted quantitatively to obtain the suitable concentration. Into a $10 \mathrm{~mL}$ calibrated flask, $0.5682 \mathrm{mM}$ concentration of ascorbic acid was prepared by dissolving $1 \mathrm{mg}$ of ascorbic acid in 1,4- dioxane accurately. It was used as standard and by maintaining the standard concentration each time $10 \mathrm{~mL}$ of 3-Amino- $N$ '-isobutyryl-6(trifluoromethyl)furo[2,3-b]pyridine-2-carbohydrazide solution was prepared. Basic structures of the alkyl derivatives of 6-(trifluoromethyl)furo[2,3-b]pyridine-2-carbohydrazide are shown below.

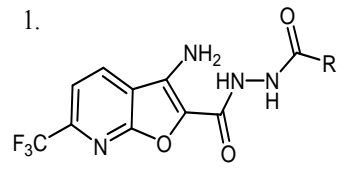<smiles>[R]C(=O)Nn1c([R])nc2c(oc3nc(C(F)(F)F)ccc32)c1=O</smiles>

Table 1. Strucutures of TEC carbohydrazide

\begin{tabular}{ccc}
\hline Compd. & $\mathrm{R}$ & $\mathrm{R} 1$ \\
\hline V1 & $-\left(\mathrm{CH}_{2}\right) 5-\mathrm{CH}_{3}$ & \\
V2 & $-\left(\mathrm{CH}_{2}\right) 4-\mathrm{CH}_{3}$ & \\
V3 & $-\mathrm{CH}^{2}\left(\mathrm{CH}_{3}\right)_{2}$ & \\
V4 & $-\left(\mathrm{CH}_{2}\right) 2-\mathrm{CH}_{3}$ & \\
V5 & $-\mathrm{CH}_{2}-\mathrm{CH}_{3}$ & \\
V6 & $-\mathrm{CH}_{2}-\mathrm{CH}_{2}\left(\mathrm{CH}_{3}\right)_{2}$ & \\
V7 & $-\mathrm{CH}_{3}$ & $-\mathrm{CH}_{3}$ \\
V8 & $-\mathrm{CH}_{2}-\mathrm{CH}\left(\mathrm{CH}_{3}\right)_{2}$ & $-\mathrm{CH}_{2}-\mathrm{CH}\left(\mathrm{CH}_{3}\right) 2$ \\
V9 & $-\left(\mathrm{CH}_{2}\right) 2-\mathrm{CH}_{3}$ & $-\left(\mathrm{CH}_{2}\right)-\mathrm{CH}_{3}$ \\
V10 & $-\left(\mathrm{CH}_{2}\right) 4-\mathrm{CH}_{3}$ & $-\left(\mathrm{CH}_{2}\right) 4-\mathrm{CH}_{3}$ \\
V11 & $-\mathrm{CH}_{2}-\mathrm{CH}_{3}$ & $-\mathrm{CH}_{2}-\mathrm{CH}_{3}$ \\
V12 & $-\mathrm{CH}_{3}\left(\mathrm{CH}_{3}\right)_{2}$ & $-\mathrm{CH}_{2}\left(\mathrm{CH}_{3}\right)_{2}$ \\
\hline
\end{tabular}

In $10 \mathrm{~mL}$ calibrated flasks, $9 \mathrm{~mL}$ of TFC analogs solution was taken and then $1 \mathrm{~mL}$ of the reagent was added. The absorbance of the solution was measured at the wave length of maximum charge transfer bands i.e. at $412 \mathrm{~nm}$ after the appropriate time interval at room temperature against reagent blank. Absorbance was recorded. Scheme 2 indicates the formation of charge transfer complex. The formed new bond was attributed to an electron transfer complexation reaction between TFC analogs as donor and chloranil as electron acceptor followed by formation of free radicals ${ }^{16}$.

Job's method of continuous variation ${ }^{17}$ was employed. Master equimolar solutions of each drug with chloranil $(80 \mathrm{mM})$ were prepared in $10 \mathrm{~mL}$ of 1,4-dioxane and the absorbance of the different concentrations was noted down. A series of $10 \mathrm{~mL}$ portions of master solutions of each drug with the acceptor was made up comprising different complementary proportions $(0: 10.1: 9,2: 8,3: 7,4: 6,5: 5,6: 4,7: 3,8: 2,9: 1,10: 0)$ in $10 \mathrm{~mL}$ calibrated flasks. 
The absorbance of the resulting solutions was measured (Figure 1) at the wavelength of maximum absorption after the appropriate time, against reagent blanks.

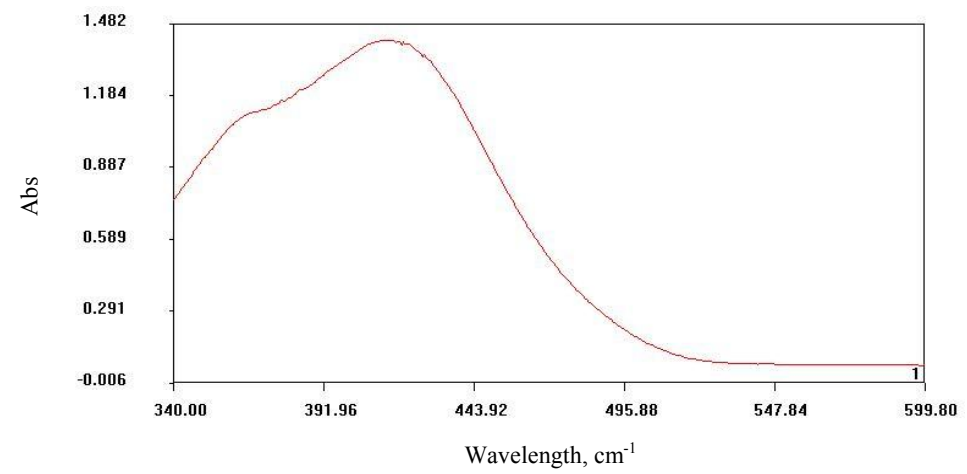

Figure 1. Absorption spectrum of 3-amino- $N^{\prime}$-isobutyryl-6-(trifluoromethyl)furo[2,3-b] pyridine-2-carbohydrazide with chloranil in 1,4-dioxane. Blank: 1,4-dioxane

Scheme 2 and 3 indicates the formation of charge transfer complex with chloranil. On studying the TFC-chloranil charge transfer complex, the formed new bond was attributed to an electron transfer complexation reaction between TFC analogs as donor and chloranil as electron acceptor followed by formation of free radicals.

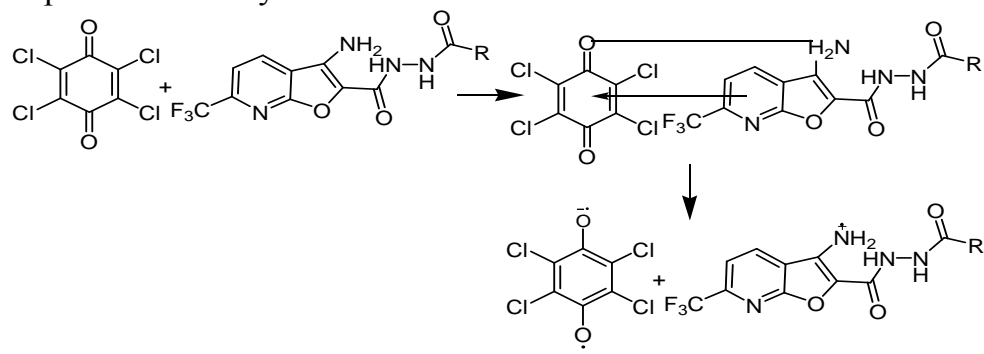

Scheme 2

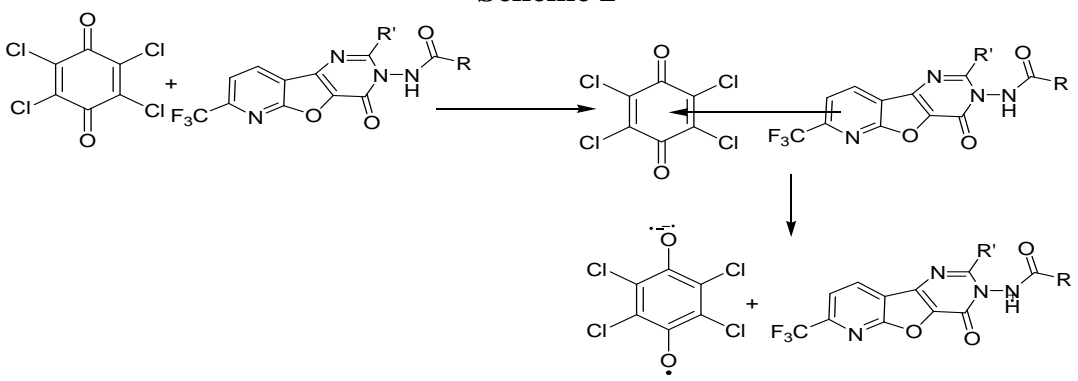

Scheme 3

\section{Association constants and standard free energy changes}

The association constants were calculated for the interaction of each drug with chloranil complex using Benesi-Hildebrand equation ${ }^{18}$.

$$
\left[\mathrm{A}_{0}\right] / \mathrm{A}^{\mathrm{AD}}=1 / \varepsilon^{\mathrm{AD}}+1 / \mathrm{K}_{\mathrm{c}}^{\mathrm{AD}} \cdot \varepsilon^{\mathrm{AD}} \times 1 /[\mathrm{Do}]
$$

Where [Ao] and [Do] are the concentrations of the acceptor and donor respectively, $\mathrm{A}^{\mathrm{AD}}$ is the absorbance of the complex, $\varepsilon^{\mathrm{AD}}$ is the molar extinction coefficient of the complex and $\mathrm{K}_{\mathrm{c}}^{\mathrm{AD}}$ is 
the association constant of the complex. From the above equation, a straight lines was obtained by plotting the values of $[\mathrm{Ao}] / \mathrm{A}^{\mathrm{AD}}$ versus $1 /[\mathrm{Do}]$. The standard free energy of complexation were calculated (Table 2) from the association constants by the following equation ${ }^{19}$.

$$
\Delta \mathrm{G}^{0}=-2.303 \mathrm{RT} \operatorname{logK\mathrm {c}^{\mathrm {AD}}}
$$

Where $\Delta \mathrm{G}^{0}$ is the free energy change of the complex in kcal/mole, $\mathrm{R}$ is the gas constant (1.987cal/mol Kelvin) $\mathrm{T}$ is the temperature in Kelvin and $\mathrm{K}_{\mathrm{c}}{ }^{\mathrm{AD}}$ is the association constant of drug-acceptor complex. The high values of association constants are common in $n$-electron donors where the inter molecular overlap may be considerable.

Table 2. Association constants and free energy changes of TFC derivatives

\begin{tabular}{ccccc}
\hline Compd. & $\mathrm{A}^{\mathrm{AD}}$ & $\varepsilon^{\mathrm{AD}}$ & $\mathrm{K}_{\mathrm{c}}^{\mathrm{AD}} \times 10^{3} \mathrm{~mol}^{-1}$ & $\Delta \mathrm{G}^{0}, \mathrm{kcal} / \mathrm{mol}$ \\
\hline $\mathbf{V}_{\mathbf{1}}$ & 0.086 & 34.4 & 292.636 & -10089.7 \\
$\mathbf{V}_{\mathbf{2}}$ & 0.066 & 26.4 & 172.352 & -9149.18 \\
$\mathbf{V}_{\mathbf{3}}$ & 0.033 & 13.12 & 42.864 & -6676.88 \\
$\mathbf{V}_{\mathbf{4}}$ & 0.093 & 37.2 & 342.213 & -10367.8 \\
$\mathbf{V}_{\mathbf{5}}$ & 0.142 & 56.8 & 797.824 & -11871.7 \\
$\mathbf{V}_{\mathbf{6}}$ & 0.198 & 79.2 & 1551.175 & -13053 \\
$\mathbf{V}_{\mathbf{7}}$ & 0.098 & 39.2 & 379.999 & -10553.9 \\
$\mathbf{V}_{\mathbf{8}}$ & 0.199 & 79.6 & 1566.883 & -13070.9 \\
$\mathbf{V}_{\mathbf{9}}$ & 0.109 & 43.6 & 470.092 & -10931.9 \\
$\mathbf{V}_{\mathbf{1 0}}$ & 0.205 & 82 & 1662.792 & -13176.4 \\
$\mathbf{V}_{\mathbf{1 1}}$ & 0.152 & 60.8 & 914.150 & -12113.5 \\
$\mathbf{V}_{\mathbf{1 2}}$ & 0.102 & 40.8 & 411.652 & -10696 \\
\hline
\end{tabular}

\section{Results and Discussion}

The infrared spectra were determined in a Perkin-Elmer Fourier transform (FTIR spectrum). ${ }^{1} \mathrm{H}$ NMR spectra were recorded on Varian EM-360 (500MHz or $300 \mathrm{MHz}$ mercury plus) spectrometer in DMSO- $\mathrm{d}_{6}$ or $\mathrm{CDCl}_{3}$ and calibrated using solvent signals $\left(7.25\left(\mathrm{CDCl}_{3}\right)\right.$ and $\left.2.50\left(\mathrm{DMSO}_{-} \mathrm{d}_{6}\right)\right)$. All chemical shifts recorded in $\delta(\mathrm{ppm})$ using TMS as an internal standard.

\section{3-Amino-N'-heptanoyl-6-(trifluoromethyl) furo [2,3-b] pyridine-2-carbohydrazide $\left(\boldsymbol{V}_{\mathbf{1}}\right)$} IR $(\mathrm{KBr}) \mathrm{cm}^{-1}$ : 3250, 3387, $\left(-\mathrm{NH}_{2}\right), 1693,1641$ (amide, $\left.\mathrm{C}=\mathrm{O}\right), 1577(\mathrm{C}=\mathrm{N}), 1528(\mathrm{C}=\mathrm{C})$. ${ }^{1} \mathrm{H}$ NMR (DMSO-d 6 , $\left.500 \mathrm{MHz}\right): \delta 0.91\left(\mathrm{t}, \mathrm{J}=6.47,3 \mathrm{H}, \mathrm{CH}_{3}\right), 1.24-1.41\left(\mathrm{~m}, 6 \mathrm{H}, 3 \times \mathrm{CH}_{2}\right)$, 1.58-1.67 (q, 2H, $\left.\mathrm{CH}_{2}\right), 2.23\left(\mathrm{t}, \mathrm{J}=7.40,2 \mathrm{H}, \mathrm{CH}_{2}\right), 6.18\left(\mathrm{~s}, 2 \mathrm{H}, \mathrm{NH}_{2}\right), 7.63(\mathrm{~d}, \mathrm{~J}=7.40,1 \mathrm{H}$, Ar-H), 8.54 (d, J=7.40, 1H, Ar-H), 9.65 (br., s, 1H, NH).

\section{3-Amino-N'-heptanoyl-6-(trifluoromethyl)furo[2,3-b]pyridine-2-carbohydrazide- chloranil complex}

IR (KBr) cm ${ }^{-1}$ : 3248, 3386, $\left(-\mathrm{NH}_{2}\right), 1690,1644$ (amide, $\left.\mathrm{C}=\mathrm{O}\right), 1573(\mathrm{C}=\mathrm{N}), 1527(\mathrm{C}=\mathrm{C})$. ${ }^{1} \mathrm{H}$ NMR (DMSO-d $6,500 \mathrm{MHz}$ ): $\delta 6.16$ (br., s, 2H, NH2), 7.64 (d, J=7.70, 1H, Ar-H), 8.52 (d, J=7.70, 1H, Ar-H), 9.56 (br., s, 1H, NH) 9.70 (br., s, 1H, NH).

\section{3-Amino- $N$ '-hexanoyl-6-(trifluoromethyl)furo[2,3-b]pyridine-2-carbohydrazide $\left(\boldsymbol{V}_{2}\right)$}

IR $(\mathrm{KBr}) \mathrm{cm}^{-1}$ : 3248, 3385, $\left(\mathrm{NH}_{2}\right), 1693,1641$ (amide, $\left.\mathrm{C}=\mathrm{O}\right), 1577(\mathrm{C}=\mathrm{N}), 1528(\mathrm{C}=\mathrm{C})$. ${ }^{1} \mathrm{H}$ NMR (DMSO-d $\left.\mathrm{d}_{6}, 500 \mathrm{MHz}\right): \delta 0.91\left(\mathrm{t}, \mathrm{J}=6.98,3 \mathrm{H}, \mathrm{CH}_{3}\right), 1.28-1.40\left(\mathrm{~m}, 4 \mathrm{H}, 2 \times \mathrm{CH}_{2}\right)$, 1.56-1.69 (q, 2H, $\left.\mathrm{CH}_{2}\right), 2.22\left(\mathrm{t}, \mathrm{J}=7.55,2 \mathrm{H}, \mathrm{CH}_{2}\right), 6.30\left(\mathrm{~s}, 2 \mathrm{H}, \mathrm{NH}_{2}\right), 7.71(\mathrm{~d}, \mathrm{~J}=7.74,1 \mathrm{H}$, Ar-H), 8.60 (d, J=7.74, 1H, Ar-H), 9.71 (br., s, 1H, NH), 9.89 (br., s, 1H, NH). 


\section{3-Amino-N'-hexanoyl-6-(trifluoromethyl)furo[2,3-b] pyridine-2-carbohydrazide- chloranil complex}

IR $(\mathrm{KBr}) \mathrm{cm}^{-1}$ : 3250, 3378, $\left(\mathrm{NH}_{2}\right), 1687,1645$ (amide, $\left.\mathrm{C}=\mathrm{O}\right), 1570(\mathrm{C}=\mathrm{N}), 1536(\mathrm{C}=\mathrm{C})$.

${ }^{1} \mathrm{H}$ NMR (DMSO-d $6,500 \mathrm{MHz}$ ): $\delta 6.12$ (br., s, 2H, NH2), 8.50 (d, J=8.06, 1H, Ar-H), 9.39

(br., s, 1H, NH), 9.65 (br., s, 1H, NH).

$\mathrm{N}$-(3-isobutyl-1-oxo-7-(trifluoromethyl)pyrido[3',2':4,5] furo[3,2-d]pyrimidin-2(1H) -yl)-3-methylbutanamide $\left(\boldsymbol{V}_{\boldsymbol{8}}\right)$

IR (KBr) cm ${ }^{-1}: 3184\left(\mathrm{NH}_{2}\right), 1699$ (amide, $\left.\mathrm{C}=\mathrm{O}\right), 1549(\mathrm{C}=\mathrm{N}) .{ }^{1} \mathrm{H}$ NMR $\left(\mathrm{CDCl}_{3}, 300 \mathrm{MHz}\right): \delta$ $0.99\left(\mathrm{~d}, \mathrm{~J}=6.71,6 \mathrm{H}, 2 \times \mathrm{xCH}_{3}\right), 1.03\left(\mathrm{~d}, \mathrm{~J}=6.61,6 \mathrm{H}, 2 \times \mathrm{CH}_{3}\right), 2.20-2.39\left(\mathrm{~m}, 4 \mathrm{H}, 2 \times \mathrm{CH}_{2}\right), 2.66-2.85$ (m, 2H, 2xCH) 7.84 (d, J=7.93, 1H, Ar-H), 8.64 (d, J=7.93, 1H, Ar-H) 8.79 (br., s, 1H, NH).

$\mathrm{N}$-(3-isobutyl-1-oxo-7-(trifluoromethyl)pyrido[3',2':4,5] furo[3,2-d]pyrimidin-2(1H) -yl)-3-methylbutanamide-chloranil complex

IR $(\mathrm{KBr}) \mathrm{cm}^{-1}: 3220(\mathrm{NH}), 1688$ (amide, $\left.\mathrm{C}=\mathrm{O}\right), 1568(\mathrm{C}=\mathrm{N}) .{ }^{1} \mathrm{H}$ NMR $\left(\mathrm{CDCl}_{3}, 300 \mathrm{MHz}\right): \delta$ $7.86(\mathrm{~d}, \mathrm{~J}=7.93,1 \mathrm{H}, \mathrm{Ar}-\mathrm{H}), 8.19$ (br s, 1H, NH) 8.64 (d, J=7.93, 1H, Ar-H).

The ${ }^{1} \mathrm{H}$ NMR data of the charge transfer complexes of $\mathrm{V}_{1}, \mathrm{~V}_{2}$ and $\mathrm{V}_{8}$ were compared with the $\mathrm{V}_{1}, \mathrm{~V}_{2}$ and $\mathrm{V}_{8}$ molecules. In $\mathrm{V}_{1}$ complex the $\delta$ chemical shifts of all protons are changed to $\delta$ 6.16 (br., s, 2H, NH2), 7.64 (d, J=7.70, 1H, Ar-H), 8.52 (d, J=7.70, 1H, Ar-H), 9.56 (br., s, 1H, $\mathrm{NH}) 9.70$ (br., s, $1 \mathrm{H}, \mathrm{NH}$ ). In $\mathrm{V}_{2}$ complex the $\delta$ chemical shifts of all protons are changed to $\delta$ 6.12 (br., s, 2H, $\mathrm{NH}_{2}$ ), 8.50 (d, J=8.06, 1H, Ar-H), 9.39 (br., s, 1H, NH), 9.65 (br., s, 1H, NH). In $\mathrm{V}_{8}$ complex the $\delta$ chemical shifts of all protons are changed to $\delta 7.86(\mathrm{~d}, \mathrm{~J}=7.93,1 \mathrm{H}, \mathrm{Ar}-\mathrm{H})$, 8.19 (br s, $1 \mathrm{H}, \mathrm{NH}) 8.64(\mathrm{~d}, \mathrm{~J}=7.93,1 \mathrm{H}, \mathrm{Ar}-\mathrm{H})$. The $\delta$ chemical shifts of all protons are decreased because the electron densities around the molecules were decreased by attracting towards chloranil side. So, it is the best evidence for the formation of charge transfer complex.

IR spectrum of $V_{1}, V_{2}$ and $V_{8}$ complexes

The IR Spectrum of $V_{1}, V_{2}$ and $V_{8}$ complexes are compared with the $V_{1}, V_{2}$ and $V_{8}$ molecules. The IR spectra of $\mathrm{V}_{1}$ complex wave numbers changed to 3248, 3386, $\left(-\mathrm{NH}_{2}\right), 1690$, 1644(amide, $\mathrm{C}=\mathrm{O}), 1573(\mathrm{C}=\mathrm{N}), 1527(\mathrm{C}=\mathrm{C})$. The IR spectra of $\mathrm{V}_{2}$ complex wave numbers changed to 3250, 3378, $\left(\mathrm{NH}_{2}\right), 1687,1645$ (amide, $\left.\mathrm{C}=\mathrm{O}\right), 1570(\mathrm{C}=\mathrm{N}), 1536(\mathrm{C}=\mathrm{C})$. The IR spectra of $\mathrm{V}_{8}$ complex wave numbers changed to3220 $(\mathrm{NH}), 1688$ (amide, $\left.\mathrm{C}=\mathrm{O}\right), 1568(\mathrm{C}=\mathrm{N})$. This wave number decreased is due to formation of charge transfer complex. These conclusions are also supported by the intensity of the charge transfer complexes were shifted towards lower intense side. This is conformed that the new bond is formed between oxygen atoms of the chloranil to the amine functional group of the $\mathrm{V}_{2}$ molecule.

TFC analogs were tested for charge transfer complex with chloranil in the present experimental studies. In the $\mathrm{V}_{3}$ complex the association constant is nearly 40 times lower than the association constant of the $\mathrm{V}_{8}$ complex is due to the stable structure of the sample. The rapid development of colours at room temperature with non-corrosive reagents, the intensity, sensitivity and the stability of colours suggest obvious use of this method for the detection of the complexation studies of the title compounds.

\section{Conclusion}

A spectrophotometric method for the determination of charge transfer complex of the TFC analogs using chloranil as reagent was studied in the present investigations. The present study, therefore confirms the suitability of chloranil for spectrophotometric analysis of title compound in the micro range. 


\section{Acknowledgement}

Authors are thankful to The Head, Department of Chemistry, University College of Science, Saifabad, Osmania University, for providing the facilities for the research work.

\section{References}

1. Haga N, Nakajima H, Takayanagi H and Tokumaru K, J Org Chem., 1998, 63, 53725384.

2. Mulliken R S and Person W B, Molecular Complexes A Lecture and Reprint Volume; Wiley \& Sons: New York, 1969.

3. Torrance J B, Girlando A, Mayerle J J, Crowley J I, Lee V Y and Batail P, Phys Rev Lett., 1981, 47(24), 1747-1750.

4. Murata T, Morata Y, Fukui K, Sato K, Shiomi D, Takui T, Angew Chem Int Ed Engl., 2004, 43(46), 6343-6346.

5. Hughes R C and Soos Z G, J Chem Phys., 1968, 5, 1066-1076.

6. $\quad$ Girlando A, Painelli A and Pecile C J, Chem Phys., 1988, 89(1), 494-503.

7. Carper W R, hedges R M and Simpson H N, J Phys Chem., 1965, 69, 1707-1710.

8. Liao M S, Lu Y, Parker V D, Scheiner S J, Phys Chem A, 2003, 107, 8939-8948.

9. Hamed M M A, Abdel- Hamid M I, Mahmoud M R, Monatshefle Fur Chemie., 1998, 129, 121-127.

10. Bhattacharya S, Ghosh K, Basu S and Benerjee M, J Solution Chem., 2006, 35(4), 519-539.

11. Foster R, In Organic Charge Transfer Complexes, Academic press, London, 1969, 51, 387.

12. Melby L R, in Patai (Ed.), The Chemistry of the Cyano group, New York, 1970, 1-1044.

13. Rao C N R, Bhat S N, Dwivedi P C, in Brame E G (Ed.), Applied Spectroscopy, Reviews, Dekker, New York, 1972, 5, 1-170.

14. Rakesh Sharma, Mukesh Paliwal, Sadhana Singh, Rameshwer Ameta and Suresh C, Ameta, Indian J Chem Technol., 2008, 15, 613-616.

15. Delagado J N and Remers W A, (Eds.), Wilson and Gisfold's Textbook of Organic Medicinal and Pharmaceutical Chemistry, $9^{\text {th }}$ Ed., Lippincott-Raven Publishers, Philadelphia, NY, 1991, p.413.

16. Hesham Salem, J Pharm Biomed Anal., 2002, 29, 527-538.

17. Rose J, Advanced Physicochemical Experimental, Pittman, London, 1964, p.54.

18. Benesi H A and Hidelbrand J, J Am Chem Soc., 1949, 71, 2703.

19. Martin A N, Swarbrick J and Cammarata A, Physical Pharmacy, $3^{\text {rd }}$ Ed., Lee \& Febiger, Philadelphia, PA, 1969, 344. 